\title{
Do We Share an Understanding of Transdisciplinarity in Environmental Sustainability Research?
}

Tomohiko Sakao and Sergio Brambila-Macias

The self-archived postprint version of this journal article is available at Linköping University Institutional Repository (DiVA):

http://urn.kb.se/resolve?urn=urn:nbn:se:liu:diva-142361

N.B.: When citing this work, cite the original publication.

Sakao, T., Brambila-Macias, S., (2018), Do We Share an Understanding of Transdisciplinarity in Environmental Sustainability Research?, Journal of Cleaner Production, 170, 1399-1403.

https://doi.org/10.1016/j.jclepro.2017.09.226

Original publication available at:

https://doi.org/10.1016/j.jclepro.2017.09.226

Copyright: Elsevier

http://www.elsevier.com/

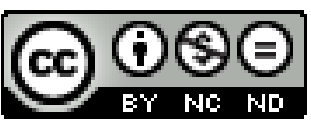




\title{
Do We Share an Understanding of Transdisciplinarity in Environmental Sustainability Research?
}

\author{
Tomohiko Sakao* and Sergio A. Brambila-Macias \\ Division of Environmental Technology and Management, Department of Management and \\ Engineering, Linköping University, Sweden \\ * Corresponding author (Tel: +46 73620 9472, Email: tomohiko.sakao@liu.se) \\ (Word count: 3,563)
}

Note that this manuscript is submitted as a letter to the editor (4,000 words at maximum), and not as one of the other categories such as original research or review article. In addition, it intends to serve as an editorial note for a virtual special issue (VSI) containing the six articles referred to in this letter.

\section{Introduction}

Problem solving in the context of sustainability has been described as complex, ill-structured or even "wicked", and in need of cooperation across disciplines (Wahl and Baxter, 2008). Therefore, it is natural that JCLP embraces transdisciplinarity. JCLP indeed officially states that it serves as a transdisciplinary forum for the exchange of information and research concepts, policies, and technologies. However, is the term transdisciplinary clearly understood, and is the understanding shared by the authors and audience? This letter raises this question, provides a way of understanding it within this community, argues for the importance of addressing this question and lastly comments on several articles published in JCLP in relation to this question.

To do so, this letter first introduces definitions from the academic literature regarding transdisciplinary as well as interdisciplinary and multidisciplinary (see Section 2). Second, it explains why an understanding of transdisciplinarity, as well as the differences between the three terms mentioned above, are important, and how such an understanding will enhance the research and practice in the topics of the entire journal (see Section 3). Third, taking environmental sustainability design research as an example subject, it shows several articles published in the journal that do and do not comply with commonly accepted definitions, and shows the relevance of this issue within this example subject (see Section 4). Overall, this letter is expected to contribute to enhance the quality of the scientific debate in the journal, and eventually the related practice in industry.

\section{Transdisciplinary, interdisciplinary and multidisciplinary research}

As suggested earlier, JCLP is described as an international transdisciplinary journal that through its publications aims to help societies become more sustainable. This section argues that there is a lack of clarity when referring to transdisciplinary research, and therefore a need for clarifying its meaning. In order to clarify what transdisciplinary research means, this section aims at describing and discussing this and similar terms that are related to cooperation across disciplinary boundaries. By doing so, it is expected that a clearer view can be created to help in identifying transdisciplinary research in the context of environmental sustainability research.

A plethora of terms and definitions can be found in the literature (Mauser et al., 2013). One of the earliest international efforts to classify and find consensus regarding collaboration among 
disciplines can be found at a seminar on higher education held in 1970 and organized by the Organisation of Economic Cooperation and Development (OECD) (Klein, 1990; Klein, 2004). The findings of the seminar were later published in 1972 (Apostel, 1972). The report contains definitions of terms such as discipline, multidisciplinary, interdisciplinary and transdisciplinary. The focus is understood to be on interdisciplinary rather than transdisciplinary research. Table 1 shows the definitions as described in the report.

Table 1. Definitions by Guy Michaud for the OECD report on higher education in 1972.

\begin{tabular}{|l|l|}
\hline Term & Definition \\
\hline Discipline & $\begin{array}{l}\text { A specific body of teachable knowledge with its own background of education, } \\
\text { training, procedures, methods and content areas. }\end{array}$ \\
\hline Multidisciplinary & $\begin{array}{l}\text { Juxtaposition of various disciplines, sometimes with no apparent connection } \\
\text { between them, e.g. music, mathematics, and history. }\end{array}$ \\
\hline Interdisciplinary & $\begin{array}{l}\text { An adjective describing the interaction among two or more different disciplines. } \\
\text { This interaction may range from simple communication of ideas to the mutual } \\
\text { integration of organising concepts, methodology, procedures, epistemology, } \\
\text { terminology, data, and organisation of research and education in a fairly large field. } \\
\text { An interdisciplinary group consists of persons trained in different fields of } \\
\text { knowledge (disciplines) with different concepts, methods, and data and terms } \\
\text { organised into a common effort on a common problem with continuous } \\
\text { intercommunication among the participants from the different disciplines. }\end{array}$ \\
\hline Transdisciplinary & $\begin{array}{l}\text { Establishing a common system of axioms for a set of disciplines (e.g. anthropology } \\
\text { considered as "the science of man and his accomplishments") }\end{array}$ \\
\hline
\end{tabular}

Since then, other institutions have provided reports to summarize and provide guidance regarding these terms. Two examples are The National Academies of Sciences (2005) and The National Research Council (2014) in the USA, which provided definitions, discussions and advice on how to manage research that goes beyond disciplinary boundaries. With the information provided in these reports, as well as relevant publications, the following descriptions are provided.

Firstly, multidisciplinary research refers to research that includes more than one discipline, and where each discipline makes a separate contribution. In this type of research, investigators may share research approaches while still working on different aspects of a common problem. Once the problem or project comes to an end, the different disciplines remain unchanged. Secondly, interdisciplinary research can be described as occurring when researchers from two or more disciplines integrate information, data, tools, perspectives, concepts, and/or theories to solve problems whose solutions are beyond disciplinary boundaries. At the end of an interdisciplinary endeavour, the different disciplines will have obtained insight into how to solve a problem with a different perspective coming from the opposite discipline(s). Finally, transdisciplinary research is one that transcends disciplines with comprehensive frameworks, or by employing a systemic view. These descriptions of multidisciplinary, interdisciplinary and transdisciplinary research are in line with and complementary to OECD's definitions in Table 1. In addition, Figure 1 depicts the differences between the three notions. 


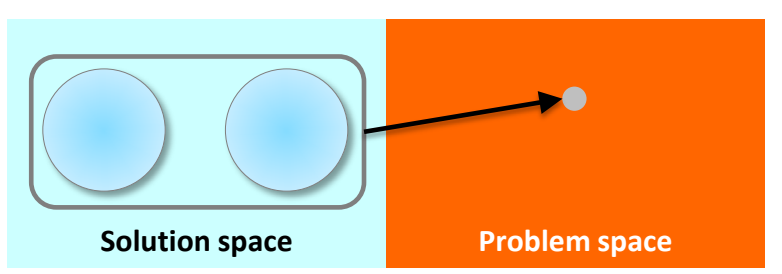

(a) Multidisciplinary

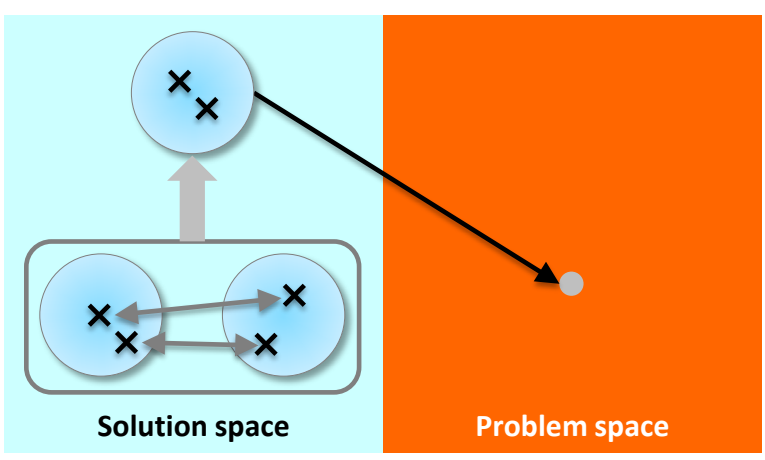

(c) Transdisciplinary 1

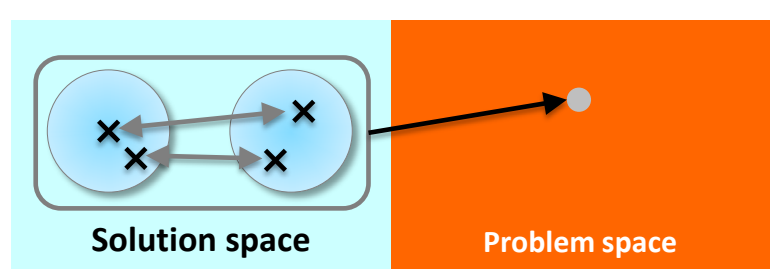

(b) Interdisciplinary

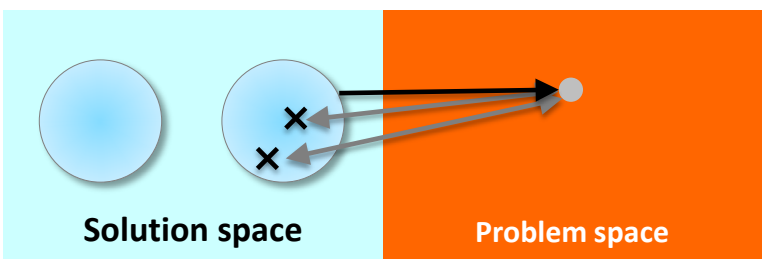

(d) Transdisciplinary 2

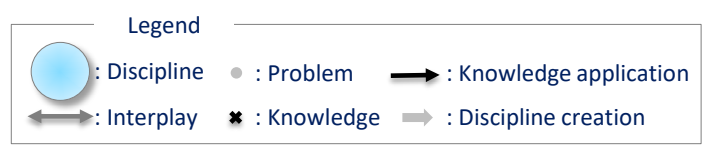

Figure 1. Differences between multi-, inter-, and transdisciplinary research (partly based on Cronin, 2008).

With regard to transdisciplinary research, its later interpretation emphasises problem solving for "real world" problems in need of creative or innovative solutions. The definition of transdisciplinary research seems to be the farthest from consensus among academics. It has been described as contentious (Pohl, 2010), most desirable but difficult to obtain (Stock and Burton, 2011) and far from academically established (Jahn et al., 2012). Due to this lack of consensus, Pohl (2011) provides four features of transdisciplinarity: relating to socially relevant issues, transcending and integrating disciplinary paradigms, participatory research, and searching for a unity of knowledge. It might be understood that transdisciplinary research has two directions. One is developing a more general and common body of knowledge beyond the disciplines (let us call this Transdisciplinary 1). The other is inclusion of non-academic stakeholders, which according to Pohl (2011) have been influential in Europe in the last decade; this results in what is known as "Mode 2" knowledge production (Gibbons et al., 1994) where academic and non-academic partners temporarily collaborate in teams and disintegrate once the problem is solved (let us call this Transdisciplinary 2).

\section{Why and how a shared understanding of transdisciplinarity helps}

Sustainability challenges require new ways of knowledge production in research and decisionmaking in practice (see Lang et al., 2012). They influence each other, and therefore the interaction between the academic and non-academic is important, corresponding to Transdisciplinary 2. At the same time, the research and practice requires using insights in multiple disciplines in new ways (Wahl and Baxter, 2008). This corresponds to Transdisciplinary 1 . Therefore, environmental sustainability research can be regarded as a kind of transdisciplinary research, as discussed in Section 2. Clearly, sharing understanding of 
transdisciplinary research as such will help to enhance the quality of environmental sustainability research in the community, because they have a parent-child class relationship.

Is such a shared understanding important then? There are a number of articles supporting the importance. The shared understanding fundamentally helps communication first and foremost. For instance, the effects of a lack of shared understanding of integrative research are shown by Tress et al. (2005) in landscape research: the absence presents a barrier to integration and communication among researchers. For example, project participants cannot exchange views when integrative research concepts are used differently, or the lack of common understanding of the terms may present difficulties when comparing and evaluating results. On the other hand, establishing clearer explanation of what "Transdisciplinary" means could provide a "body of knowledge" or "grey matter" and hopefully a "how-to" approach to carry out transdisciplinary research and better address research grants from sponsoring organizations. Collaboration could be based on focusing on the problem at hand, and what contribution could be made and what methods should be used by different stakeholders.

Next, how is the shared understanding helpful? In sustainability science, Brandt et al. (2013) point out that transdisciplinary research must be clearly framed with common terminology and appropriate methods. They provide five key challenges to transdisciplinary approaches: first, lack of coherent framing; second, integration of methods; third, research process and knowledge production; fourth, practitioners' engagement; and fifth, generating impact. These challenges are also questioned regarding to what extent transdisciplinary approaches are actually being fully implemented and acknowledged in sustainability science research (ibid). In more general terms, learning and exploiting insights on transdisciplinary research will help environmental sustainability research, because the latter inherits the former.

For environmental sustainability research, the clarification of the notion of transdisciplinary research could hence clarify what problems it addresses and what tools or methods it employs. Clarifying transdisciplinarity in one of the leading journals of environmental sustainability research could enhance discussions in all the above aspects and, perhaps more importantly, could question our own assumptions, leading to a higher level of understanding, knowledge creation and complex problem solving in reality.

Having addressed the why and how above, let us also touch upon where we should be heading. Here, an indirect answer is provided to the question: a good example of development of research and practice in the past will help with envisioning the development of environmental sustainability research. An example of tackling complexity and real-world problems can be seen in what is today known as materials science and engineering. Bensaude-Vincent (2001) suggests that the aggregation of metallurgy, mechanical, chemical and electrical engineering, as well as industrial applications, customer demands and government support, saw the rise of this discipline in the 1960s. In his best-seller publication, Amato (1997) suggests that this discipline needed more than interdisciplinary synergism, and that it would take collaboration and mastering of different disciplines to transcend traditional differences and create powerful partnerships. A "superdiscipline", as Amato calls it, can hence transcend and be equipped with necessary theories, methods and tools for solving complex problems. Brown et al. (2010) and Amato (1997) suggest that space travel is an example of how collaboration across disciplines, government funding and industrial incentives play a vital role in achieving results. There are 
more examples such as mechatronics, which emerged from mechanics and electronics. We hope this helps you to envision where we should be heading.

\section{Commenting on JCLP example articles on design}

Taking environmental sustainability design, often called design for sustainability (including Ecodesign ${ }^{1}$ and Product/Service System design) as an example subject of JCLP, this section brings us to a more concrete discussion. Both Transdisciplinary 1 and 2 are relevant in the design-for-sustainability context. The reason for that can be understood by a definition of ecodesign and an explanation of engineering design, of which ecodesign is a subset. Ecodesign is defined as the integration of environmental aspects into product design and development, with the aim of reducing adverse environmental impacts throughout a product's life cycle (ISO, 2011). Therefore, ecodesign makes use of knowledge in environmental science or natural science (and partly social science) at large in product design and development or engineering. This means that ecodesign as such is a transdisciplinary activity and a target of "Transdisciplinary 1" research. Engineering design can be explained as a complex, multifaceted phenomenon involving 1) people, a developing product, and a process involving a multitude of activities and procedures; 2) a wide variety of knowledge, tools and methods; 3 ) an organization; and 4) a micro-economic and macro-economic context (Blessing and Chakrabarti, 2010). This also means that ecodesign is an activity in industry, and thus research in ecodesign requires cooperation between academia and industry (meaning "Transdisciplinary 2 " research). It may be more suitable to state that transdisciplinarity is the essence of Ecodesign and research in Ecodesign.

This does not deny the relevance of interdisciplinary or multidisciplinary research in Ecodesign; rather, the opposite is true. An editorial note of an Ecodesign special issue on JCLP (Karlsson and Luttropp, 2006) provided a broader definition of ecodesign than that by ISO (ISO, 2011). It concludes that ecodesign is about design in and for a sustainable development context, after acknowledging some other definitions of ecodesign addressing acceptable societal demands (e.g. (Charter et al., 2001)). It provides an opportunity for multidisciplinary or interdisciplinary research in Ecodesign based on the engineering and social science disciplines, for instance. This is in line with the need of considering both the production and consumption sides of sustainable development (see a special issue on JCLP (Luskin and Blackman, 2007)). These two disciplines of engineering and social science are raised here as examples, and other disciplines such as engineering and history might also be of relevance.

Looking at JCLP articles on design for sustainability in the context of multi-, inter- and transdisciplinarity, one example from multidisciplinary research can be found in Byers et al. (2015): this article applied portfolio theory in the finance discipline to nonfinancial assets, which are in this case a pool of physical products, often a part of Product/Service System design, to increase resource efficiency. This article is clearly multidisciplinary. It is, however, not regarded as interdisciplinary, because the integration of organising concepts, procedures, and terminology is not clearly seen. Interdisciplinary research, on the other hand, was conducted and spoken about in Deutz et al. (2013), which contributed to a greater understanding of ecodesign practice in industry through a social science study of an engineering practice. Importantly, the authors deconstructed the design process, rather than treating it as a black box.

\footnotetext{
${ }^{1}$ In this article, the word ecodesign is capitalized when referring to the area in literature. Referring to ecodesign as a design activity does not require it be capitalized.
} 
This makes their research interdisciplinary instead of multidisciplinary. This could be also seen as transdisciplinary research because of their collaboration with industry. However, it is assumed that the degree of collaboration was limited by the conducted survey, and thus did not lead the authors to call it transdisciplinary research. On the other hand, Gonzalez-Garcia et al. (2012) used the terms multidisciplinary team and interdisciplinary team to refer to an identical team for ecodsign. This can be understood as they worked with an interdisciplinary team, however sticking to one term based on a common understanding will be more straightforward.

Moving to transdisciplinarity, it may be suitable to refer first to Baumann et al. (2002). They did not use the term transdisciplinary or transdisciplinarity; however, what they argued for, based on a literature study of green product development, is understood as the need for transdisciplinary research over the engineering, policy and business disciplines (Transdisciplinary 1). In Bergeå et al. (2006), one can discern two main disciplines: one is sustainability, the other product design and development. In their effort to incorporate more sustainability knowledge into product design and development in a $\mathrm{PhD}$ course on Ecodesign, the authors also include participants from industry. Their results suggest that multiple perspectives are necessary to tackle "real-world" problems. Additionally, they suggest that reflection on theories, methods and epistemic questions is necessary to achieve transformative learning in people and organisations, and that this effort takes time to render results: corresponding to Transdisciplinary 2.

Regarding Transdisciplinary 1, Allais et al. (2015) can be seen as establishing a common system of axioms for two disciplines. They incorporated territorial resources into the product development process. The authors made use of two case studies that show that by including territory as a resource, local value creation for the customer, company and territory can be achieved. The authors concluded that their approach requires significant changes from the stakeholders; where customers have to balance costs with other values, companies need to change their strategic and operational practices while being supported by policies with local perspectives. They made a proposition for the integration of what is typically addressed in Industrial Symbiosis and Ecodesign. The authors called this multi-disciplinary research. However, it can be called transdisciplinary research based on the discussion in Section 2.

\section{Concluding remarks}

This letter to the editor has postulated that there is a need to clarify the statement of the journal as an international transdisciplinary platform for research in the sustainability paradigm. It also provided an understanding of transdisciplinary research based on the literature, and named the two directions of transdisciplinary research as Transdisciplinary 1 and 2. Based on the discussion in Sections 3 and 4, the two directions were indeed found to be relevant in the environmental sustainability research.

One could argue that the authors' choice of words for describing research utilizing several disciplines may have little impact on the research itself; that is, as long as a problem is understood and managed across disciplines, the terms used may not be significant. However, there might be several implications in choosing one term over another. For example, the manner in which researchers understand the different terms could have an impact on how a problem is framed and how this is scoped. All of these nuances in the choice of words when referring to research across disciplines may ultimately have an impact on knowledge creation and finding the right knowledge for the right problem. 
The letter also introduced a few "Transdisciplinary 1" articles about design in the journal. It was not intended to search and show all the articles in JCLP about multi-, inter- and transdisciplinarity. Rather, the authors hope that this will trigger more effective discussion based on a shared understanding of transdisciplinarity. It should also be pointed out that Transdisciplinary 2 is highly prevalent in design articles in JCLP. Involving industry practitioners through case studies is a good example of how design-for-sustainability research is conducted. This should be regarded as an achievement worthy of praise and an asset of strength in JCLP, and should be maintained in the future to tackle real-world challenges.

"The world has problems, but universities have departments" (Brewer, 1999). We know phenomena addressed in a department silo influence phenomena studied in other silos, which is especially critical to take into account in order to enhance environmental sustainability in our societies. Byers et al. (2015), in the conclusion of their multi-disciplinary research article, stated "Different disciplines have their 'own crayons'. We suspect that the beauty of art stems from all the brush strokes collectively offering insights and perspectives." Transdisciplinary 1 research is expected to create a set of new crayons, while Transdisciplinary 2 research will improve existing crayons via collaborating with industry. The authors hope that JCLP continues to embrace knowledge creation based on transdisciplinary research to help societies become more sustainable.

\section{Acknowledgments}

This work is supported by the Mistra REES (Resource Efficient and Effective Solutions) program (DIA 2014/16), funded by Mistra (The Swedish Foundation for Strategic Environmental Research).

\section{Vitae}

Tomohiko Sakao has been professor at the Department of Management and Engineering, Linköping University, Sweden since 2007. He has been Subject Editor for Ecodesign (Environmentally Conscious Design) and Product/Service Systems in the Journal of Cleaner Production since 2014. He has published in the Journal of Cleaner Production, the Journal of Industrial Ecology, the International Journal of Life Cycle Assessment, CIRP - Manufacturing Technology, and the International Journal of Production Research, among others. Sergio A. Brambila-Macias is a $\mathrm{PhD}$ candidate at the Department of Management and Engineering, Linköping University. His research interests are in Ecodesign, Product/Service Systems and decision-making in engineering design. He is currently part of the programme Mistra REES, a four-year research programme (2015-2019) aimed at supporting Swedish companies in their efforts to provide resource-efficient and effective solutions (REES).

\section{References}

Articles to be included in the virtual special issue are shown below in bold.

Allais, R., Reyes, T., Roucoules, L., 2015. Inclusion of territorial resources in the product development process. Journal of cleaner production 94, 187-197.

Amato, I., 1997. Stuff: the materials the world is made of. Harpercollins Publishers, ISBN 9780465083282.

Apostel, L., 1972. Interdisciplinarity Problems of Teaching and Research in Universities. OECD, Paris.

Baumann, H., Boons, F., Bragd, A., 2002. Mapping the green product development field: engineering, policy and business perspectives. Journal of Cleaner Production 10, 409-425.

Bensaude-Vincent, B., 2001. The construction of a discipline: Materials science in the United States. Historical Studies in the Physical and Biological Sciences 31, 223-248. 
Bergeå, O., Karlsson, R., Hedlund-Åström, A., Jacobsson, P., Luttropp, C., 2006. Education for sustainability as a transformative learning process: a pedagogical experiment in EcoDesign doctoral education. Journal of Cleaner Production 14, 1431-1442.

Blessing, L., Chakrabarti, A., 2010. DRM, a Design Research Methodology. Springer, London.

Brandt, P., Ernst, A., Gralla, F., Luederitz, C., Lang, D.J., Newig, J., Reinert, F., Abson, D.J., von Wehrden, H., 2013. A review of transdisciplinary research in sustainability science. Ecological Economics 92, 1-15.

Brewer, G.D., 1999. The challenges of interdisciplinarity. Policy Sciences 32, 327-337.

Brown, V.A., Harris, J.A., Russell, J.Y., 2010. Tackling wicked problems through the transdisciplinary imagination. Earthscan. Abingdon, UK.

Byers, S.S., Groth, J.C., Sakao, T., 2015. Using portfolio theory to improve resource efficiency of invested capital. Journal of Cleaner Production 98, 156-165.

Charter, M., Tischner, U., al., e., 2001. Sustainable Solutions - Developing products and services for the future. Greenleaf Publishing, Sheffield.

Cronin, K., 2008. Transdisciplinary research (TDR) and sustainability. Overview report prepared for the Ministry of Research, Science and Technology (MoRST), accessed on June $18^{\text {th }}, 2017$, http://learningforsustainability.net/pubs/Transdisciplinary_Research_and_Sustainability.pdf.

Deutz, P., McGuire, M., Neighbour, G., 2013. Eco-design practice in the context of a structured design process: an interdisciplinary empirical study of UK manufacturers. Journal of Cleaner Production 39, 117-128.

Gibbons, M., Limoges, C., Nowotny, H., Schwartzman, S., Scott, P., Trow, M., 1994. The new production of knowledge: The dynamics of science and research in contemporary societies. Sage.

González-García, S., Lozano, R.G., Buyo, P., Pascual, R.C., Gabarrell, X., i Pons, J.R., Moreira, M.T., Feijoo, G., 2012. Eco-innovation of a wooden based modular social playground: application of LCA and DfE methodologies. Journal of Cleaner Production 27, 21-31.

ISO, 2011. ISO 14006:2011 Environmental management systems -- Guidelines for incorporating ecodesign, Geneva, p. 30.

Jahn, T., Bergmann, M., Keil, F., 2012. Transdisciplinarity: Between mainstreaming and marginalization. Ecological Economics 79, 1-10.

Karlsson, R., Luttropp, C., 2006. Special issue "EcoDesign: what's happening?". Journal of Cleaner Production 14, 1291-1442.

Klein, J.T., 1990. Interdisciplinarity: History, theory, and practice. Wayne state university press.

Klein, J.T., 2004. Interdisciplinarity and complexity: An evolving relationship. E:CO Emergence: Complexity and Organization 6(1-2), 2-10.

Lang, D.J., Wiek, A., Bergmann, M., Stauffacher, M., Martens, P., Moll, P., Swilling, M., Thomas, C.J., 2012. Transdisciplinary research in sustainability science: practice, principles, and challenges. Sustainability science 7, 25-43.

Luskin, J., Blackman, A.B., 2007. Special issue "Sustainable Production and Consumption-Making the Connection". Journal of Cleaner Production 15, 489-606.

Mauser, W., Klepper, G., Rice, M., Schmalzbauer, B.S., Hackmann, H., Leemans, R., Moore, H., 2013. Transdisciplinary global change research: the co-creation of knowledge for sustainability. Current Opinion in Environmental Sustainability 5, 420-431.

National Academy of Sciences, 2005. Facilitating Interdisciplinary Research, Washington, DC.

National Research Council, 2014. Convergence: Facilitating Transdisciplinary Integration of Life Sciences, Physical Sciences, Engineering, and Beyond. The National Academies Press, Washington, DC.

Pohl, C., 2010. From transdisciplinarity to transdisciplinary research. Transdisciplinary Journal of Engineering \& Science 1, 74-83.

Pohl, C., 2011. What is progress in transdisciplinary research? Futures 43, 618-626.

Stock, P., Burton, R.J., 2011. Defining terms for integrated (multi-inter-trans-disciplinary) sustainability research. Sustainability 3, 1090-1113.

Tress, B., Tress, G., Fry, G., 2005. Defining concepts and the process of knowledge production in integrative research. Springer: Heidelberg, Germany.

Wahl, D.C., Baxter, S., 2008. The designer's role in facilitating sustainable solutions. Design Issues 24, 72-83. 